\title{
Electrooxidation of methanol on doped polypyrrole films in acidic media
}

\author{
İ. Becerık ${ }^{a}$, Ş. Süzer ${ }^{b}$, F. Kadirgan ${ }^{a, *}$ \\ a Chemistry Department, Istanbul Technical University, 80626, Maslak, Istanbul, Turkey \\ ${ }^{\mathrm{b}}$ Chemistry Department, Bilkent University, 06533, Bilkent, Ankara, Turkey
}

Received 25 May 2000; received in revised form 8 November 2000; accepted 18 December 2000

\begin{abstract}
Electrooxidation of methanol was realised on platinum and perchlorate anion doped polypyrrole film electrodes in acidic media. A systematic kinetic investigation was performed and optimum experimental conditions for the preparation of the electrocatalytic system were determined. The presence of $\mathrm{ClO}_{4}^{-}$anions was confirmed by XPS analysis of the doped polymer matrix. (C) 2001 Elsevier Science B.V. All rights reserved.
\end{abstract}

Keywords: Methanol; Electrooxidation; Doping; XPS

\section{Introduction}

Many electrochemical reactions, e.g. those involved in energy conversion processes, such as fuel cells, are catalysed by electrode surfaces. The crucial role played by electrode materials was very soon recognised, particularly the effect of the adsorbed species on electrode surfaces for driving the kinetics and thermodynamics of electrochemical reactions. Therefore, most electrocatalytic reactions are controlled mainly by adsorption processes, the rates of which depend strongly on the nature and the structure of the catalytic electrode [1-7]. In order to increase the overall catalytic activity (which is proportional to the true surface area of the electrode electrolyte interface), electrode materials are usually dispersed into a convenient electron-conducting substrate (e.g. carbon powders) or on a finely divided metal, expanded metallic support (e.g. titanium grids). These lead to industrial electrodes which are used in many applications, such as fuel cells or industrial electrolyzers. However, for most of these electrode materials, the electrochemical reaction is limited to the catalytic surfaces, and the bulk material is not involved in the catalytic process. One way to circumvent this

\footnotetext{
* Corresponding author. Tel.: + 90-212-2853159; fax: +90-2122856386.

E-mail address: kadirgan@itu.edu.tr (F. Kadirgan).
}

limitation is to disperse, at the molecular level, the electrocatalytic material into a convenient electron-conducting matrix, in such a way that each catalytic centre will be accessible to the reactive molecules. This concept can be achieved by the use of an electron-conducting polymer as the conducting matrix, provided that it is sufficiently stable under the experimental conditions. It also has to be sufficiently conductive to avoid any ohmic-drop in its bulk and sufficiently porous so that there will be no mass transfer limitations for the electroactive species to reach the catalytic sites. Development of intrinsically conducting polymers [8] with almost metal-like charge transport properties has led to very efficient electrode materials. Polypyrrole (PPy) is one such conducting polymer used for electrocatalytic applications [9]. It is sufficiently conducting and stable under normal experimental conditions [10]. Many routes have been followed to use these organic conducting polymers as host matrices for incorporation of various types of ionic or molecular species which posses promising electrocatalytic properties. These include metallic particles, metal oxides, metal complexes, transition-metal macrocycles, etc. depending on the electrochemical reaction to be catalysed [11-17].

When platinum is deposited electrochemically on the PPy matrix, the particles are distributed in three dimensions within the layer [18], due to the porosity of the 
polymer. It is well known that good electronic conductivity $\left(\delta>1 \mathrm{~S} \mathrm{~cm}^{-1}\right)$ is needed in applications requiring high current densities $\left(j>100 \mathrm{~mA} \mathrm{~cm}^{-2}\right)$ in order to prevent the important ohmic-drops in the electrical circuit (leading to heat production by the joule effect and thus to a decrease in the energy efficiency). Recently, it has been shown that the properties of conducting polymer films can be altered by treatment with aqueous bases and acids [19]. Conductivity of the films decreases by more than four orders of magnitude upon modification with strong alkalis. This effect may be reversible upon treatment with strong protonic acids. Two different processes have been suggested to interpret this behaviour, i.e. counter anion exchange processes and proton transfer processes. In aqueous solution, the most mobile cationic species is the proton, and Tsai et al. [20] have reported experiments in which a PPy film was cycled in aqueous $0.1 \mathrm{M} \mathrm{LiClO}_{4}+$ $\mathrm{HClO}_{4}$ (pH 6.2), containing bromocresol purple, a $\mathrm{pH}$ indicator having a $\mathrm{p} K_{\mathrm{a}}$ of 6.2. They found that, on oxidising the PPy, proton expulsion from the film occurred and could be tracked colorimetrically. They proposed the following mechanism to account for this behaviour:

$\left[\mathrm{PPy} \cdot \mathrm{H}^{+} \cdot \mathrm{ClO}_{4}^{-}\right] \rightarrow\left[\mathrm{PPy}^{+} \cdot \mathrm{ClO}_{4}^{-}\right]+\mathrm{H}^{+}+\mathrm{e}^{-}$

and suggested the transport of different species: $\mathrm{ClO}_{4}^{-}$ and $\mathrm{H}^{+}$. Hence, the rapid ejection of protons may well be favoured over the slow incorporation of anions [19].

In this study, we present the results on the electrooxidation of methanol in acidic media, on a modified PPy film, prepared in neutral media. First of all, the oxidation of methanol is investigated on platinum-dispersed PPy in acid media and the results are compared with those of the oxidation of methanol on pure platinum under the same conditions. Then the modification of the electrocatalytic properties of the PPy matrix is made not only by incorporating platinum particles into the conducting polymer, but also by doping or dedoping it with perchlorate anions in the acidic media after the polymerisation. Finally, the kinetics of the oxidation of methanol on this modified polymer electrode are discussed. Additionally, the stability of the doped electrode in aqueous solutions will be a key factor in its practical applications. In this communication, the nature of the stability of doped PPy under oxidation conditions has also been studied.

\section{Experimental}

Electrochemical measurements were carried out using a classical experimental set-up consisting of a Wenking HP 88 Power potensiostat, a Tacussel GSTP 4 signal generator, a BBC Goerz Metrawatt $X-Y$ recorder and a Nicolet Memory oscilloscope. Electrolytic solutions were prepared from ultra pure water (Millipore Milli Q System) and Merck reagents. Pyrrole was purified by vacuum distillation and other reagents were used as received. Prior to any electrochemical preparation, a standard voltammogram was recorded to check the purity of the system. All experiments were performed using a double-walled thermostatted cell, under a nitrogen atmosphere in a three-electrode cell with a platinum electrode as the counter and a mercury $\mid$ mercurous sulfate $\mid \mathrm{K}_{2} \mathrm{SO}_{4}$ (sat) electrode (MSE) as the reference. A platinum sphere and a nickel foil were used as a substrate for the polymer film deposition. Experiments were performed mainly in acidic medium $(0.1 \mathrm{M}$ $\mathrm{HClO}_{4}$ ). The PPy films were grown by electropolymerisation in $0.1 \mathrm{M} \mathrm{LiClO}_{4}$ media at constant potential $(0.40 \mathrm{~V} / \mathrm{MSE})$. The thickness of the polymer film was estimated as $1 \mu \mathrm{m}[19,21]$. The electrochemical deposition of platinum particles on the polymer matrix was achieved from solutions containing $0.01 \% \mathrm{H}_{2} \mathrm{PtClO}_{4}$ in $0.1 \mathrm{M} \mathrm{HClO}_{4}$ by electrolysis at a constant potential after electropolymerisation. The amount of platinum deposited on to the polymer surface was calculated from the integral of the cathodic charge passed during the deposition process assuming that the reduction of $\mathrm{Pt}^{4+}$ to $\mathrm{Pt}^{0}$ is achieved with $100 \%$ efficiency during electrolysis. It has been reported that a charge $Q_{\mathrm{Pt}}$ of $200 \mathrm{mC} \mathrm{cm}^{-2}$ corresponds to a Pt loading of 100 $\mu \mathrm{g} \mathrm{cm}^{-2}$ [22]. After the films were rinsed, the growth solution was replaced by fresh $0.1 \mathrm{M} \mathrm{LiClO}_{4}$ and the films were maintained for varying durations at different times.

We have tried to observe the effect of the doped state of the polymer under positive and negative regimes. So, the inclusion of electroactive dopant $\left(\mathrm{ClO}_{4}^{-}\right)$anion is realised at $0.8 \mathrm{~V} / \mathrm{MSE}$. Dedoping of anion is performed at $-0.6 \mathrm{~V} / \mathrm{MSE}$ after the polymerisation. Both the processes are applied to the $\mathrm{PPy} / \mathrm{Pt}$ electrode surface.

Surface characterisation using X-ray photoelectron spectroscopy (XPS) measurements was carried out using a Kratos ES300 spectrometer with $\mathrm{MgK}_{\alpha} \mathrm{X}$-rays at $1253.6 \mathrm{eV}$. Polymer coated (containing the dispersed metals as well) Pt electrode samples were inserted into the vacuum chamber (vacuum lower than $10^{-8}$ Torr) and were analysed directly.

\section{Results}

There has been little work in the literature on the electrooxidation of methanol on Pt-dispersed PPy films. Therefore, first of all, we investigated and compared the oxidation of methanol on pure platinum and the $\mathrm{Pt} /$ PPy system under the same conditions, $25^{\circ} \mathrm{C}, v=$ $50 \mathrm{mV} \mathrm{s}^{-1}$ (Fig. 1). Although the shapes of the voltammograms are the same, a platinum-dispersed particle PPy film electrode shows a higher activity than 
the pure platinum. However, the oxidation of peaks A and $\mathrm{B}$ occurred slightly at more negative potentials.

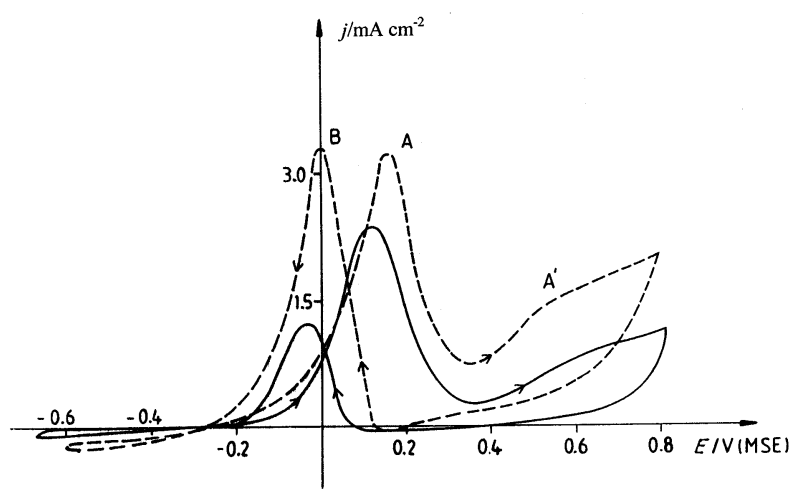

Fig. 1. Cyclic voltammogram of $0.1 \mathrm{M}$ methanol on pure platinum (-) and platinum-dispersed PPy (- -) electrodes, $0.1 \mathrm{M} \mathrm{HClO}_{4}$, $v=50 \mathrm{mV} \mathrm{s}^{-1}, m_{\mathrm{Pt}}=100 \mu \mathrm{g} \mathrm{cm}^{-2}$.

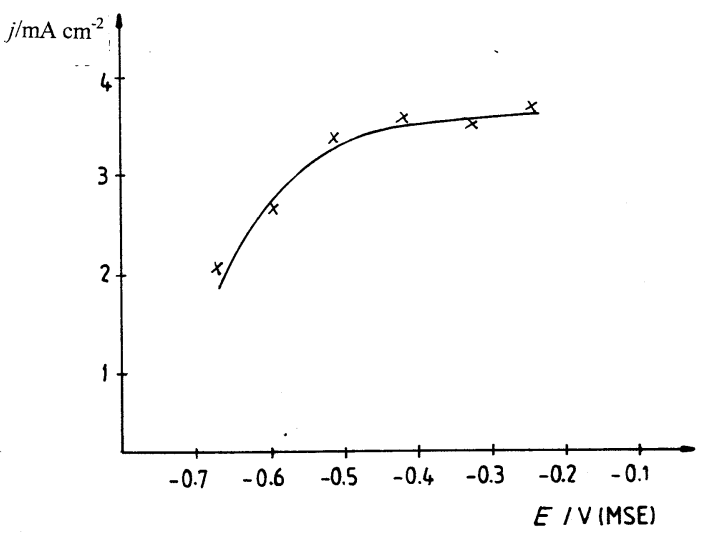

Fig. 2. Effect of platinum deposition potential on the electrooxidation of $0.1 \mathrm{M}$ methanol for the positive sweep, $v=50 \mathrm{mV} \mathrm{s}^{-1}, m_{\mathrm{Pt}}=100$ $\mu \mathrm{g} \mathrm{cm}^{-2}$.

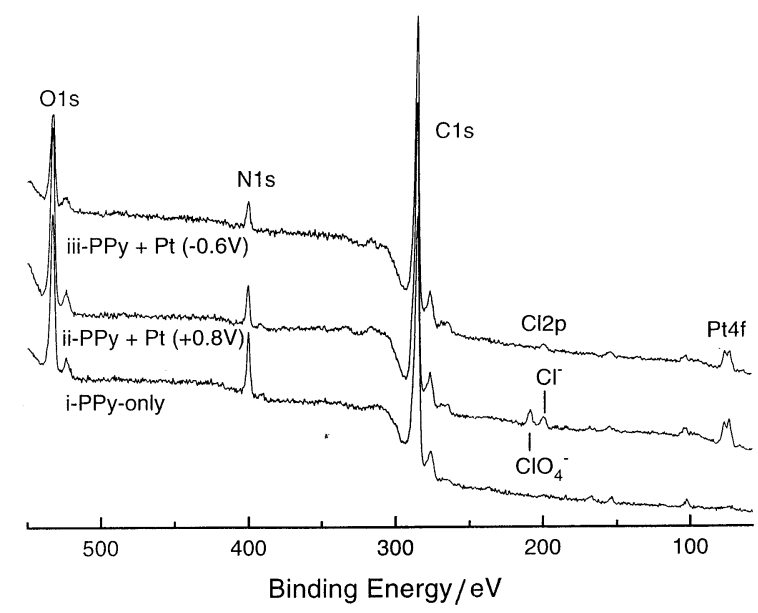

Fig. 3. XPS spectra of the electrode: (i) after PPy deposition, (ii) after $\mathrm{Pt}$ deposition, $\mathrm{ClO}_{4}^{-}$doped at $+0.8 \mathrm{~V} / \mathrm{MSE}$, and (iii) after $\mathrm{Pt}$ deposition, $\mathrm{ClO}_{4}^{-}$doped at $-0.6 \mathrm{~V} / \mathrm{MSE}$.
Next, we investigated optimum conditions of the PPy-metal particles modified system. A series of experiments was carried out as a function of platinum deposition potential at $-0.36,-0.46,-0.56,-0.66$ $\mathrm{V} / \mathrm{MSE}$ since the electrochemical deposition potential may offer control over the crystalline structure and grain morphology of the surface. It has been reported previously that [23] the maximum current density of methanol oxidation on polymer films was obtained with a Pt loading of $70-100 \mu \mathrm{g} \mathrm{cm}^{-2}$. Hence, in our study, the $\mathrm{Pt}$ loading was kept always the same at 100 $\mu \mathrm{g} \mathrm{cm}^{-2}$ and the deposition potential was varied. Meanwhile, due to the reduction of the conductivity form of the polymer at these potentials, quantitation of the amount of platinum obtained by using coulometric measurements could not be carried out. However, upper value estimates were made on the loading levels of Pt with the above data.

The effect of the platinum deposition potential on the electrooxidation of methanol was tested by recording the corresponding cyclic voltammogram after each deposition process in a solution containing $0.1 \mathrm{M}$ methanol and $0.1 \mathrm{M} \mathrm{HClO}_{4}$ with a sweep rate of 50 $\mathrm{mV} \mathrm{s}^{-1}$. Fig. 2 shows the variation of maximum anodic current densities as a function of platinum deposition potential. The current density becomes stable after the deposition potential of $-0.46 \mathrm{~V} / \mathrm{MSE}$.

Since the thin polymer film is very porous, one may suspect that the Pt substrate may also play a catalytic role during oxidation. In order to check whether there is any effect of the Pt substrate on the oxidation of methanol on a Pt-dispersed PPy coated electrode, we carried out two types of experiments [9]:

1. We recorded the surface sensitive XPS spectra of Pt (substrate)/PPy and $\mathrm{Pt}$ (substrate)/PPy/Pt electrodes. No peak related to $\mathrm{Pt}$ was observed in the case of PPy, only the system as shown in Fig. 3i.

2. We checked the oxidation of methanol on a Pt-dispersed PPy coated nickel substrate (Ni (substrate)/ $\mathrm{PPy} / \mathrm{Pt}$ electrode) and obtained a comparable current intensity in comparison to the Pt (substrate)/ $\mathrm{PPy} / \mathrm{Pt}$ electrode. These observations prove that the substrate does not play a role in the electrooxidation of methanol on the polymer matrix (Fig. 4).

3. We also checked whether there was any diffusion of methanol through the $\mathrm{Pt} / \mathrm{PPy}$ film and whether this was oxidised at the Pt substrate even when there was no Pt XPS signal arising from the Pt substrate. The true surface areas of the doped and the nondoped electrodes were the same in the supporting electrolyte.

The stability of the Ni/PPy/Pt system in acid media was investigated by examining the successive voltammograms of the electrode (Fig. 5). After 100 cycles, the electrode displayed good stability.

Then, the oxidation of methanol on the doped and the non-doped Pt modified PPy electrodes was investi- 


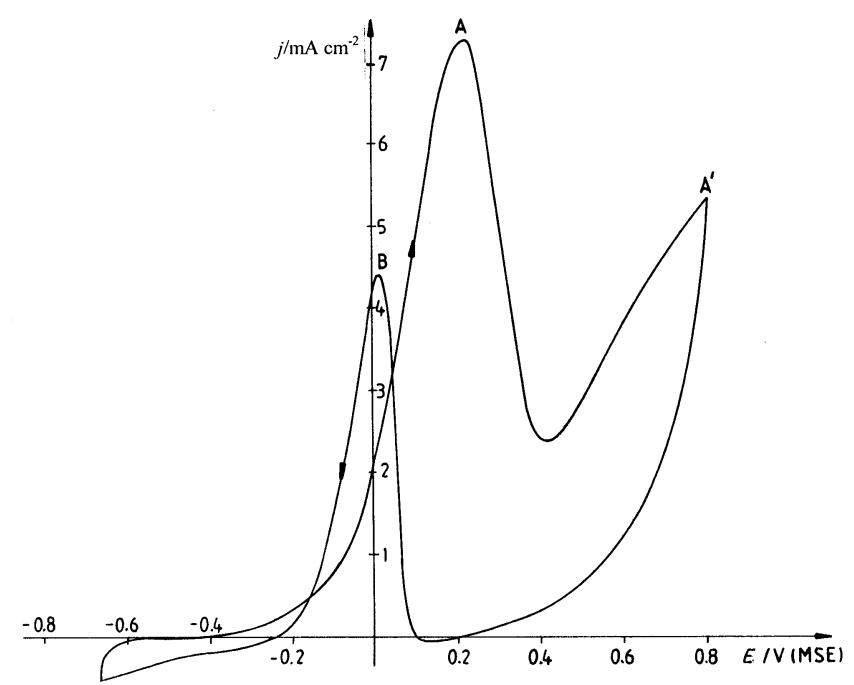

Fig. 4. Cyclic voltammogram of $0.1 \mathrm{M}$ methanol on Ni (substrate)/ PPy $/ \mathrm{Pt}$ electrode $v=50 \mathrm{mV} \mathrm{s}^{-1}, m_{\mathrm{Pt}}=100 \mu \mathrm{g} \mathrm{cm}^{-2}$.

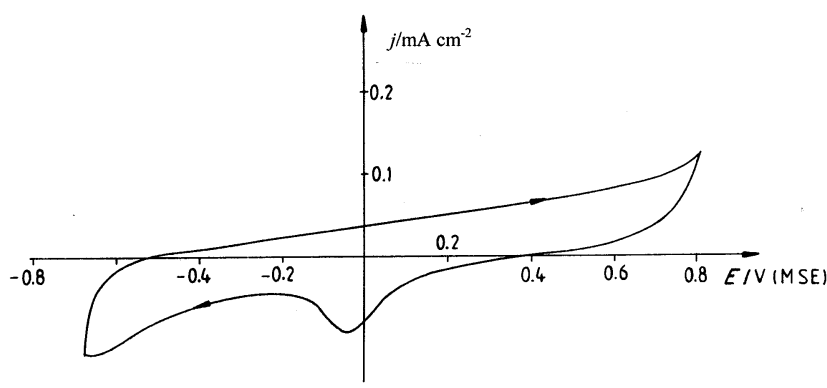

Fig. 5. The stability of $\mathrm{Ni}$ (substrate) $/ \mathrm{PPy} / \mathrm{Pt}$ electrode in $0.1 \mathrm{M}$ $\mathrm{HClO}_{4}$ after 100 cycles $v=50 \mathrm{mV} \mathrm{s}{ }^{-1}, m_{\mathrm{Pt}}=100 \mu \mathrm{g} \mathrm{cm}^{-2}$.

gated. When it was studied as a function of doping or dedoping time for perchlorate ions at 0.8 or -0.6 V/MSE, respectively, it was observed that $15 \mathrm{~min}$ was the best doping or dedoping time to obtain the highest current density for methanol electrooxidation. The oxidation of methanol on the non-doped platinum modified PPy and the doped PPy electrodes at optimum conditions are depicted in Fig. 6. During the positive scan, an oxidation peak (A) and a shoulder $\mathrm{A}^{\prime}$ are observed at more positive potentials compared to that of the non-doped surface. Throughout the reverse scan, oxidation peak (B) is also obtained at a slightly more positive potential than that of the non-doped surface. We observed an approximately 2.5 -fold increase in the current density during the oxidation of methanol, when the PPy matrix was doped with $\mathrm{ClO}_{4}^{-}$anion at 0.8 $\mathrm{V} / \mathrm{MSE}$ relative to the non-modified surface (Fig. 6). However, the maximum current density is lower in the case of the dedoped surface at $-0.6 \mathrm{~V} / \mathrm{MSE}$ than that of the doped surface at $0.8 \mathrm{~V} / \mathrm{MSE}$. The methanol oxidation overpotential is also decreased during the negative sweep in the case of the doped matrix surface.
Doping of PPy was checked by XPS measurements. In Fig. 3ii the XPS spectra of the Pt (substrate)/PPy/Pt electrode doped with $\mathrm{ClO}_{4}^{-}$electrode at $+0.8 \mathrm{~V}$ is given. In addition to the strong $\mathrm{Pt} 4 \mathrm{f}$ peak a strong $\mathrm{Cl}$ $2 p$ peak at around $207 \mathrm{eV}$ binding energy which is assigned to $\mathrm{ClO}_{4}^{-}$is observed. However, no strong $\mathrm{ClO}_{4}^{-}$could be observed at $-0.6 \mathrm{~V}$ as is shown in Fig. 3iii.

The Pt-dispersed $\mathrm{ClO}_{4}^{-}$doped $\mathrm{PPy}$ electrode also displayed good stability for the electrooxidation of methanol. No change in current density was observed during methanol oxidation for 100 cycles. We also checked the stability by recording $\mathrm{CVs}$ of the same electrode in the supporting electrolyte. The same shape was obtained.

The effect of the perchlorate ion doping on the platinum-dispersed PPy matrix is non-negligible. For this reason, we investigated the kinetics of methanol oxidation on the doped surface and compared the results with methanol oxidation on the non-doped Ptdispersed PPy electrode.

The effects of the upper and lower limits of the potential were also investigated for both the doped and the non-doped matrix (Figs. 7 and 8). An increase of the upper limit $\left(E_{\mathrm{a}}\right)$ produces a slight augmentation of the current density of peak A on the positive sweep on the doped surface (Fig. 7a). No decrease is observed during the negative sweep $\left(E_{\mathrm{c}}\right)$ at peak B except at 1.2 $\mathrm{V} / \mathrm{MSE}$. However, the current density of peak A does not change during the increase of the upper limit in the

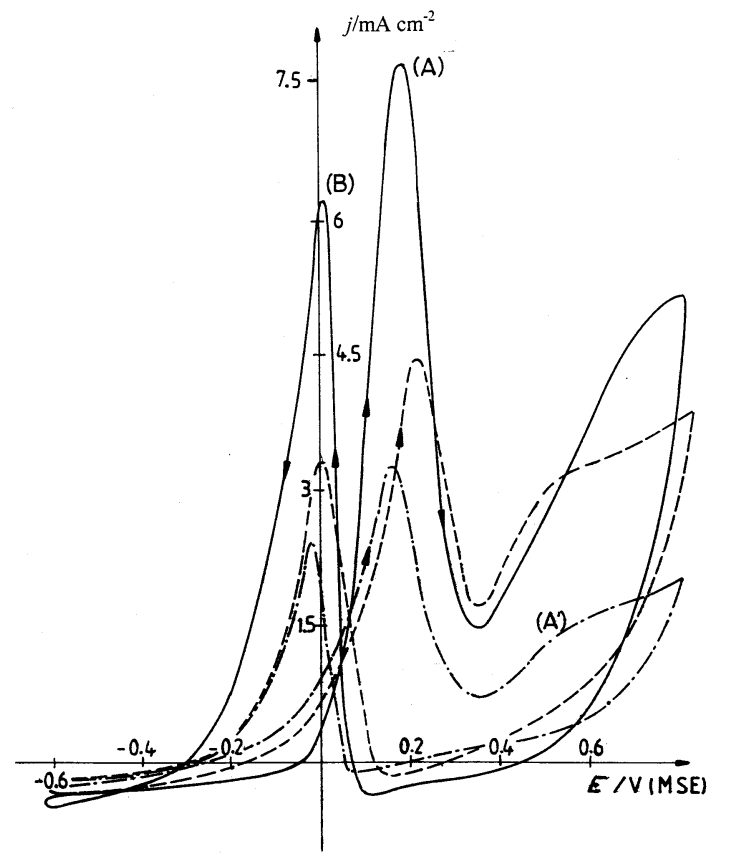

Fig. 6. Cyclic voltammogram of $0.1 \mathrm{M}$ methanol $(-\cdot-\cdot)$ before doping, (-) doping at $0.8 \mathrm{~V} / \mathrm{MSE},(---)$ doping at $-0.6 \mathrm{~V} / \mathrm{MSE}$, $t_{\text {doping }}=15 \mathrm{~min}, v=50 \mathrm{mV} \mathrm{s}^{-1}, m_{\mathrm{Pt}}=100 \mu \mathrm{g} \mathrm{cm}^{-2}$. 


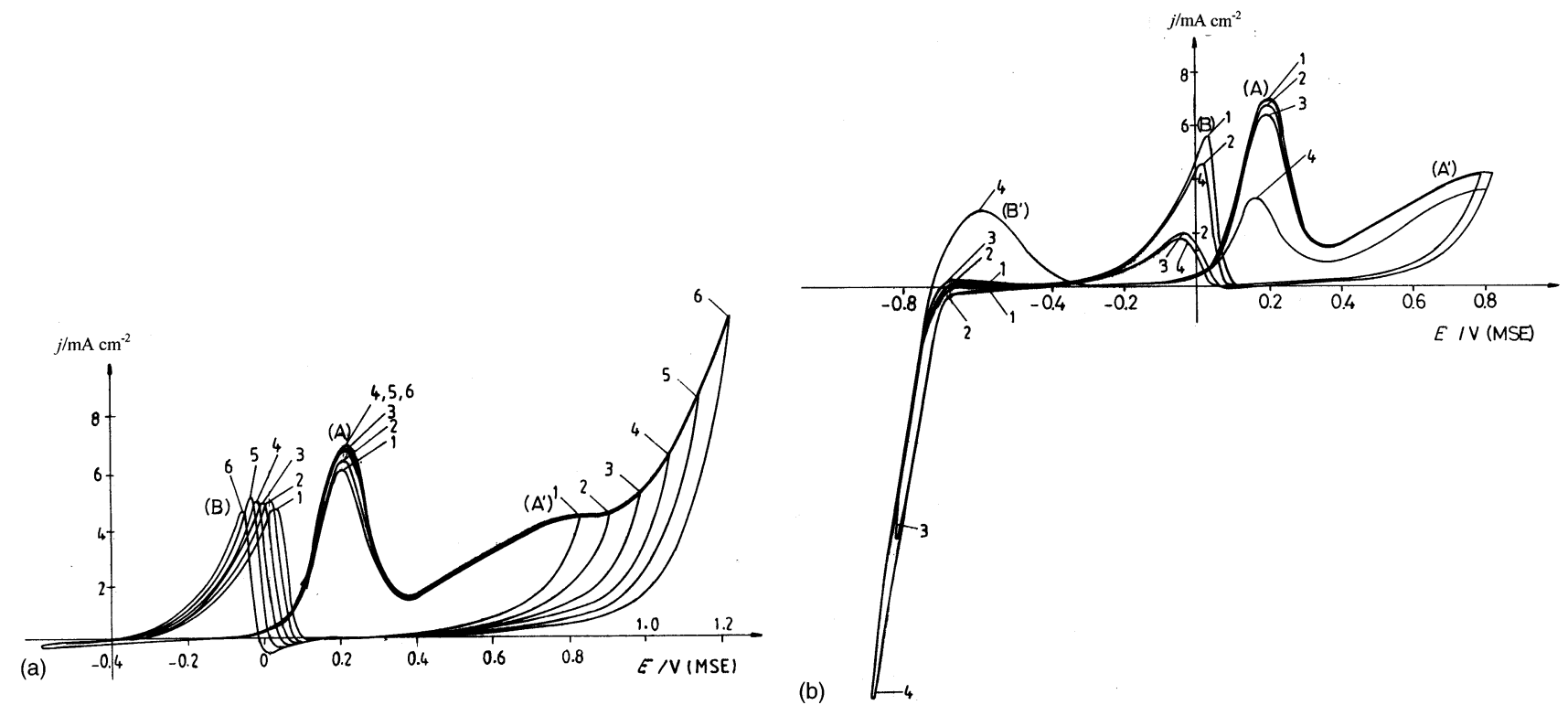

Fig. 7. (a) Effect of the positive sweep on the electrooxidation of $0.1 \mathrm{M}$ methanol for the doped state, $v=50 \mathrm{mV} \mathrm{s}-1, t_{\mathrm{d}}=15 \mathrm{~min}, m_{\mathrm{Pt}}=100$ $\mu \mathrm{g} \mathrm{cm}^{-2}$. (b) Effect of the negative sweep on the electrooxidation of $0.1 \mathrm{M}$ methanol for the doped state, $v=50 \mathrm{mV} \mathrm{s}-1, t_{\mathrm{d}}=15 \mathrm{~min}, m_{\mathrm{Pt}}=100$ $\mu \mathrm{g} \mathrm{cm}^{-2}$.
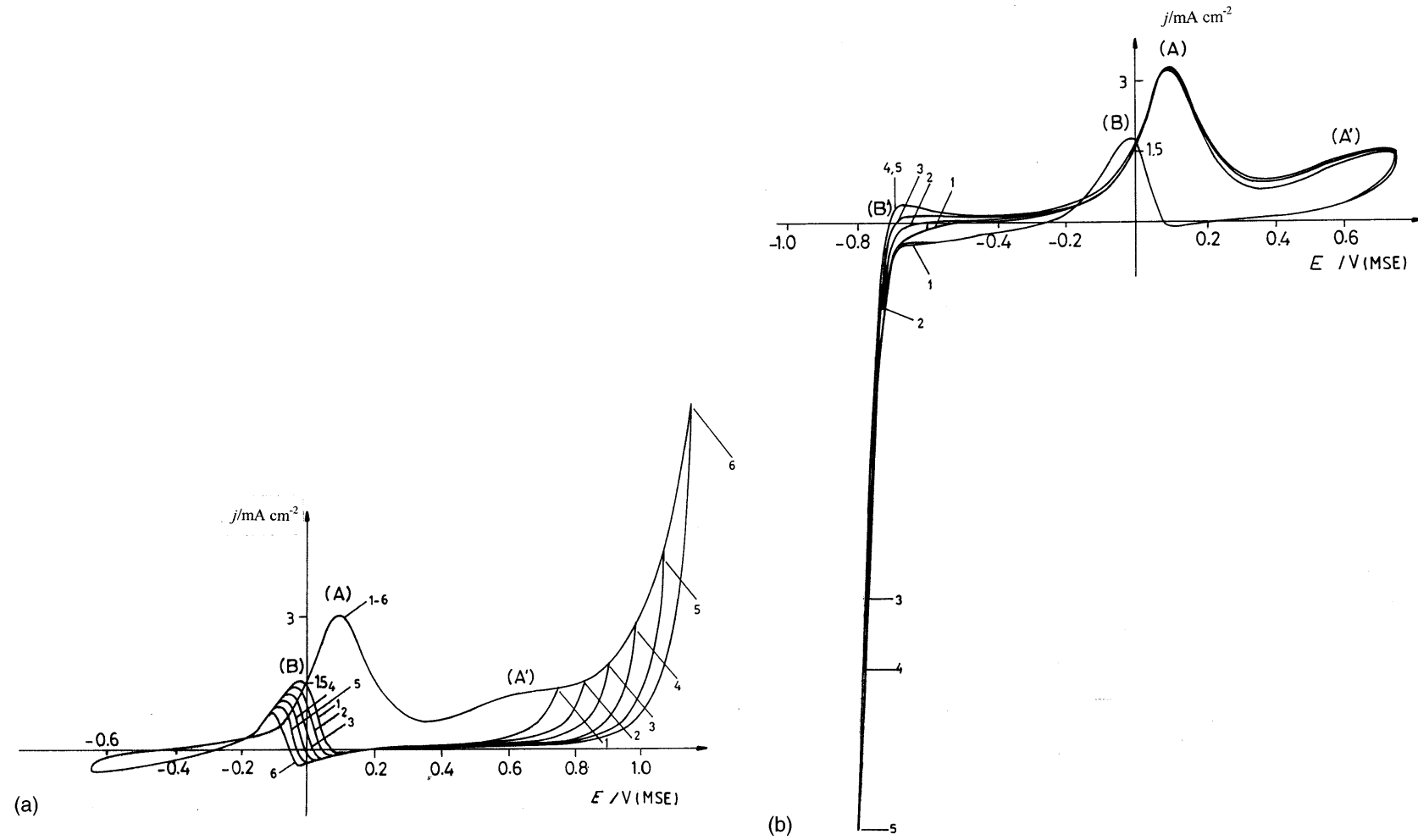

Fig. 8. (a) Effect of the positive sweep on the electrooxidation of $0.1 \mathrm{M}$ methanol for the undoped state, $v=50 \mathrm{mV} \mathrm{s}{ }^{-1}, t_{\mathrm{d}}=15 \mathrm{~min}, m_{\mathrm{Pt}}=100$ $\mu \mathrm{g} \mathrm{cm}^{-2}$. (b) Effect of the negative sweep on the electrooxidation of $0.1 \mathrm{M}$ methanol for the undoped state, $v=50 \mathrm{mV} \mathrm{s}{ }^{-1}, t_{\mathrm{d}}=15 \mathrm{~min}, m_{\mathrm{Pt}}=100$ $\mu \mathrm{g} \mathrm{cm}^{-2}$.

case of the non-doped surface while the current density of peak B decreases (Fig. 7a). If we compare the $j_{\mathrm{p}}^{\mathrm{a}} / j_{\mathrm{p}}^{\mathrm{c}}$ ratio as a function of $E_{\mathrm{a}}$ for the doped and the undoped surfaces, it is observed that $j_{\mathrm{p}}^{\mathrm{c}}$ becomes closer to $j_{\mathrm{p}}^{\mathrm{a}}$ values as $E_{\mathrm{a}}$ is increased to more positive values in the case of the doped electrode matrix (Table 1). This may be explained by the increase of oxygen overvoltage in the case of the doped surface. However, we have to 
note that the oxidation of methanol also begins at a more positive potential on the doped surface than that of the non-doped surface.

Table 1

Ratio of the $j_{\mathrm{p}}^{\mathrm{a}} / j_{\mathrm{p}}^{\mathrm{c}}$ for the doped and the undoped states

\begin{tabular}{lll}
\hline$E / \mathrm{V}(\mathrm{MSE})$ & $j_{\mathrm{p}}^{\mathrm{a}} / j_{\mathrm{p}}^{\mathrm{c}}($ doped state $)$ & $j_{\mathrm{p}}^{\mathrm{a}} / j_{\mathrm{p}}^{\mathrm{c}}$ (undoped state) \\
\hline 0.7 & 1.29 & 1.91 \\
0.8 & 1.27 & 2.35 \\
0.9 & 1.38 & 2.67 \\
1.0 & 1.41 & 2.05 \\
1.1 & 1.53 & 3.64 \\
\hline
\end{tabular}

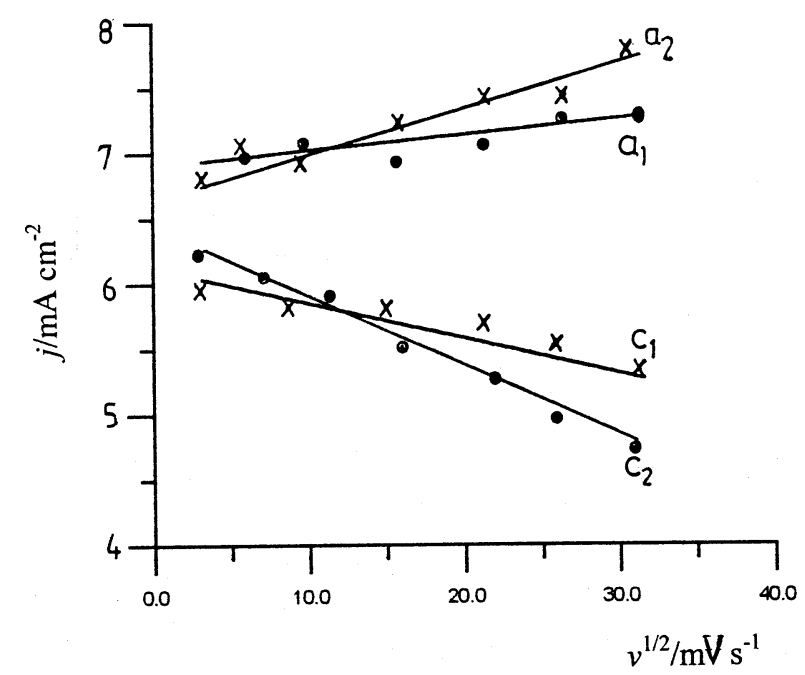

Fig. 9. Peak current dependence vs square root of scan rate at $\mathrm{PPy} / \mathrm{Pt}$ electrode $0.1 \mathrm{M}$ Methanol + $0.1 \mathrm{M} \mathrm{HClO}_{4} ;\left(\mathrm{a}_{1}\right)$ for the positive sweep before doping, $\left(a_{2}\right)$ for the positive sweep after doping, $\left(c_{1}\right)$ for the negative sweep before doping, $\left(\mathrm{c}_{2}\right)$ for the negative sweep after doping.

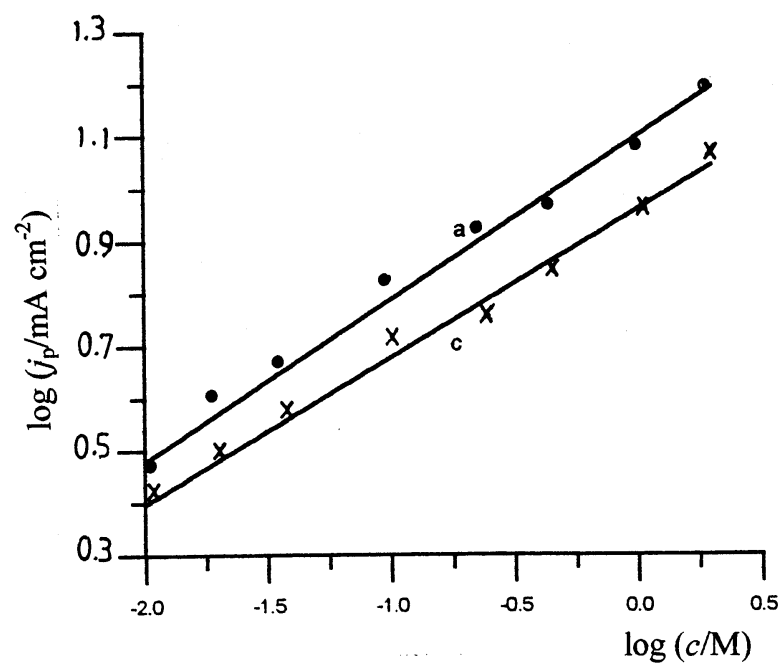

Fig. 10. Plot of the peak current dependence vs the logarithm of methanol concentration on a $\mathrm{PPy} / \mathrm{Pt}$ electrode doped with $\mathrm{ClO}_{4}^{-}$ anions, $t_{\mathrm{d}}=15 \mathrm{~min}, m_{\mathrm{Pt}}=100 \mu \mathrm{g} \mathrm{cm}^{-2}, v=50 \mathrm{mV} \mathrm{s}^{-1}$; (a) positive sweep, (c) negative sweep.
While the effect of the lower limit variation is negligible for the non-doped surface (Fig. 8b), it is remarkably large for the doped surface. At a more negative potential, a peak $\left(\mathrm{A}^{\prime}\right)$ corresponding to the oxidation of hydrogen is obtained at the doped surface. As a result of the oxidation of hydrogen, the current densities of peaks A and B decrease. Hence, one may assume that either the hydrogen overvoltage is decreased or the methanol is more dehydrogenated in the case of the doped surface.

We also have investigated the variation of the sweep rate from 0.01 to $1.0 \mathrm{~V} \mathrm{~s}^{-1}$ for $0.1 \mathrm{M}$ methanol oxidation both on the doped and the undoped surface. Fig. 9 shows the variation of maximum current density $\left(\log j_{\mathrm{p}}\right)$ vs. $v^{1 / 2}$ for both positive and negative sweeps in the doped and the undoped states. The current densities vary linearly with increasing scan rate at both positive and negative sweeps. However, $j$ is independent of $v$ in the case of the doped surface. These facts certainly suggest that the electron transfer is reversible (because $v^{1 / 2}$ is independent of $E_{\mathrm{p}}$ ) for both the positive and the negative peaks, but it is controlled by adsorption on the doped surface.

The concentration of methanol was varied from 0.01 to $2 \mathrm{M}$ in $0.1 \mathrm{M} \mathrm{HClO}_{4}$ aqueous solutions on the doped surface. With increasing concentration, peaks A and B were shifted towards more positive potentials and their current densities were enhanced. Shoulder $\mathrm{A}^{\prime}$ was more intense when the concentration was greater than $0.1 \mathrm{M}$. Plots of the logarithm of current density $(\log j)$ vs. the $\operatorname{logarithm}$ of concentration $(\log c)(\mathrm{M})$ give the overall reaction order with respect to the initial concentration of methanol on the doped surface (Fig. 10). The reaction order, derived from the slope of the straight line is 0.31 for the positive and 0.28 for the negative sweep. Tafel plot analysis of the left-hand side of the first oxidation peak (A) is also realised (Fig. 11). The $\alpha n$ values calculated from the slopes of the straight lines are given in Table 2 . They $(\alpha n)$ are approximately 0.5 indicating a one electron transfer $(n=1$, if we assume $\alpha=0.5)$.

\section{Conclusions}

- The electrooxidation of methanol on platinum microparticule incorporated PPy films on platinum or nickel electrodes was reported. They were found to give higher current densities than electrodes of pure platinum.

- The studies in acidic media may be compared to similar reports on other dispersed metal-polymer systems. Kost et al. [24] report current densities of about $1 \mathrm{~mA} \mathrm{~cm}{ }^{-2}$ for $2-5 \mu \mathrm{m}$ thick polyaniline films 


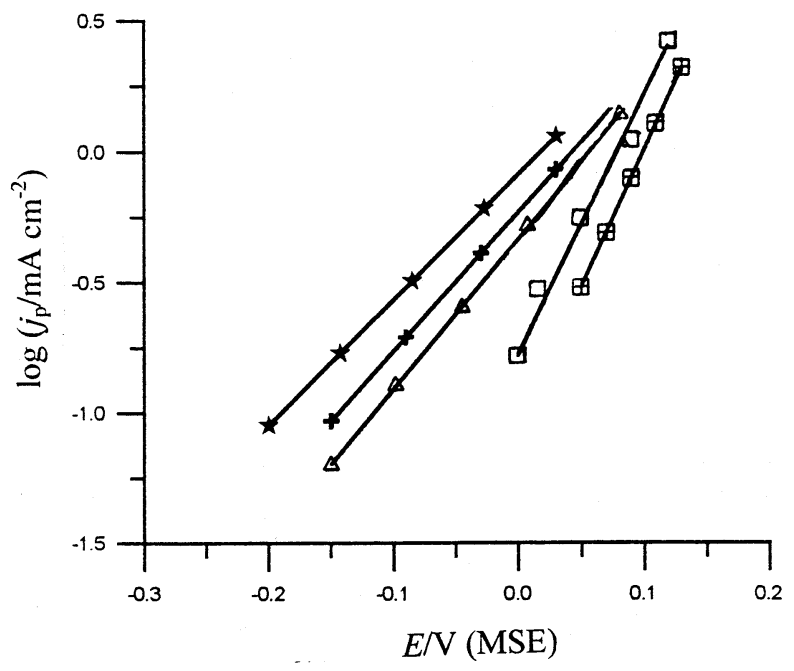

Fig. 11. Tafel plots (the peak current dependence vs potential) at different methanol concentrations, $0.1 \mathrm{M} \mathrm{HClO}_{4}, v=50 \mathrm{mV} / \mathrm{s}\left(^{*}\right)$ $0.01 \mathrm{M},(+) 0.02 \mathrm{M},(\triangle) 0.03 \mathrm{M},(\square) 0.5 \mathrm{M}$, (田) $2 \mathrm{M}$.

Table 2

Transfer coefficients for the electrooxidation of methanol on the $\mathrm{PPy} / \mathrm{Pt}$ electrode on the doped surfaces

\begin{tabular}{llllll}
\hline$c_{\mathrm{M}} / \mathrm{M}$ & $\alpha n$ & $c_{\mathrm{M}} / \mathrm{M}$ & $\alpha n$ & $c_{\mathrm{M}} / \mathrm{M}$ & $\alpha n$ \\
\hline 0.01 & 0.25 & 0.05 & 0.41 & 0.5 & 0.60 \\
0.02 & 0.32 & 0.1 & 0.60 & 1 & 0.54 \\
0.03 & 0.34 & 0.2 & 0.54 & 2 & 0.62 \\
\hline
\end{tabular}

modified with $30 \mu \mathrm{g} \mathrm{cm}^{-2}$ of platinum, recorded at $600 \mathrm{mV} / \mathrm{Ag} \mid \mathrm{AgCl}$ and in $1.0 \mathrm{M} \mathrm{H}_{2} \mathrm{SO}_{4}$ containing 1.0 M methanol, whilst Aramata and Ohnishi [25] report current densities of about $20 \mu \mathrm{A} \mathrm{cm}^{-2}$ (geometric area) for Nafion ${ }^{\circledR}$ films about $200 \mu$ m thick loaded with $4-8 \mathrm{mg} \mathrm{cm}^{-2}$ of platinum, recorded in $1.0 \mathrm{M} \mathrm{H}_{3} \mathrm{PO}_{4}$ containing $1.0 \mathrm{M}$ methanol at 600 $\mathrm{mV} /$ RHE. In other work, current densities of around $2 \mathrm{~mA} \mathrm{~cm}{ }^{-2}$ were obtained after running the electrodes for $12 \mathrm{~h}$ in $0.1 \mathrm{M} \mathrm{H}_{2} \mathrm{SO}_{4}$ or $1.0 \mathrm{M} \mathrm{HClO}_{4}$ containing $1.0 \mathrm{M}$ methanol at $500 \mathrm{mV} / \mathrm{SCE}$ using electrodes composed of a $300 \mathrm{~nm}$ PPy film modified with about $200 \mu \mathrm{g} \mathrm{cm}^{-2}$ of platinum [26]. Methanol electrooxidation on a PPy film modified with platinum microparticles on glassy carbon electrodes was studied by means of electrochemical and in situ Fourier transform infrared techniques [27]. The platinum microparticles were incorporated into the PPy film using cyclic voltammetry. It was observed from SEM micrographs (not shown) and XPS spectra that the Pt microparticles existed not only on the surface of the PPy film, but also inside the film. In addition, a certain interaction between the Pt microparticles and PPy was seen. The catalytic activities were found to be dependent on Pt loading and the thickness of the PPy film. Determining the amount of Pt de- posited at the $\mathrm{PPy} / \mathrm{C}$ electrode was done by atomic absorption spectrophotometry. A maximum current density of approximately $150 \mathrm{~mA} \mathrm{~cm}^{-2}$ with 148.9 $\mu \mathrm{g} \mathrm{cm}^{-2} \mathrm{Pt}$ loading in $0.5 \mathrm{M} \mathrm{CH}_{3} \mathrm{OH}+0.5 \mathrm{M}$ $\mathrm{H}_{2} \mathrm{SO}_{4}$ at $25^{\circ} \mathrm{C}$ was used. The enhanced electrocatalytic activities are explained as being due to the uniform dispersion of Pt microparticles in the PPy film and the synergistic effects of the highly dispersed Pt microparticles and the PPy film.

- According to our XPS results, Pt particles are dispersed on the surface of the polymer.

- The stability of the above electrodes was checked in acid medium and it was observed that they display a good stability.

- Upon further anodic oxidation in the reversible potential region, the polymer is transformed to the radical cation and anions are inserted into the solid to maintain electroneutrality. So, $\mathrm{ClO}_{4}^{-}$anions are entrapped via Coulombic interaction with the positively charged polymer segments keeping their electrocatalytic properties.

- The presence of $\mathrm{ClO}_{4}^{-}$anions is confirmed by XPS analysis on the doped polymer matrix at $+0.8 \mathrm{~V} /$ MSE.

- We have checked the doped surface on a Ni substrate by XPS and no peak assignable to the substrate could be observed.

- The kinematically fast proton expulsion that takes place in the early part of the oxidation process is superseded at higher potentials by the thermodynamically favoured influx of anions.

- The stability of the $\mathrm{ClO}_{4}^{-}$doped $\mathrm{Pt} / \mathrm{PPy} / \mathrm{Ni}$ electrodes is found to be good.

- The doped electrodes exhibited better electrocatalytic activity when compared with $\mathrm{Pt} / \mathrm{PPy} / \mathrm{Ni}$ or $\mathrm{Pt}$.

- It has been suggested [28] that the high activity of polyaniline films modified with platinum for the oxidation of formate stems from metal-polymer interactions which inhibit the formation of strongly chemisorbed species. An alternative mechanism is that the longevity of platinum microparticles in anion or cation exchange membranes stems from an ability of the membranes to stabilise the surface media for the $\left(\mathrm{Pt}^{0} / \mathrm{Pt}^{2+}\right)$ couple [25]. From the present results, it is unclear whether both of these mechanisms apply in the current case. Additionally, it is well known that the counterion can effect the PPy film morphology and the conductivity [29]. So, the higher activity obtained with $\mathrm{ClO}_{4}^{-}$doped $\mathrm{Pt}$ / $\mathrm{PPy} / \mathrm{Pt}-\mathrm{Ni}$ electrodes may be explained as due to the protective effect against the poisoning reactions of methanol oxidation by an increase in the conductivity and change in morphology when compared with platinum dispersed in PPy films.

- The degrees of freedom available to modify the electrochemical properties of a polymer by changing 
the counterion open up the possibility of tailoring the polymer electrode to achieve a number of desired properties.

In conclusion, the above results show that $\mathrm{ClO}_{4}^{-}$ion doped platinum-dispersed PPy displays interesting electrocatalytic properties.

\section{References}

[1] B. Beden, C. Lamy, J.M. Leger, in: J.O’M Bockris, B.E. Conway, R. White (Eds.), Modern Aspects of Electrochemistry, vol. 22, Plenum Press, New York, 1992, pp. 97-264.

[2] J.O'M. Bockris, A.K.N. Reddy, Modern Electrochemistry, vol. 2, Plenum Press, New York, 1972, p. 1141.

[3] F.C. Anson, Acc. Chem. Res. 8 (1975) 400.

[4] M.W. Breiter, Adsorption of organic species on platinum metal electrodes, in: J.O'M. Bockris, B.E. Conway (Eds.), Modern Aspects of Electrochemistry, vol. 10, Plenum Press, New York, 1975, pp. 161-210 (Ch. 3).

[5] A.J. Appleby, Electrocatalyts, in: B.E. Conway, J.O'M Bockris (Eds.), Modern Aspects of Electrochemistry, vol. 9, Plenum Press, New York, 1974, p. 369.

[6] B.B. Damaskin, O.A. Petri, V.N. Batrakoxv, Adsorption of Organic Compounds on Electrodes, Plenum Press, New York, 1971 p. 175.

[7] G.P. Sakellarpoulos, in: D.D. Eley, H. Pines, P.B. Weisz (Eds.), Surface Reactions and Selectivity in Electrocatalysis, vol. 30, Academic Press, New York, 1981, p. 218.

[8] T.A. Skotheım, Handbook of Conducting Polymers, Marcel Dekker, New York, 1985 p. 327.
[9] İ. Becerık, Ş. Süzer, F. Kadirgan, J. Electroanal. Chem. 476 (1999) 171.

[10] K.K. Kanazawa, A.F. Diaz, W.D. G1ll, P. Grant, G.B. Street, G.P. Gardini, J.F. Kwak, Synth. Met. 1 (1979) 329.

[11] N. Oyama, F.C. Anson, J. Electrochem. Soc. 127 (1980) 247.

[12] N. Oyama, K. Shigehara, F.C. Anson, Inorg. Chem. 20 (1981) 518.

[13] N. Oyama, F.C. Anson, J. Electrochem. Soc. 127 (1980) 640.

[14] H.D. Abruna, T.J. Meyer, R.W. Murray, Inorg. Chem. 11 (1979) 3233.

[15] F. Beck, M. Dalhaus, J. Appl. Elctrochem. 23 (1993) 781.

[16] H. Yoneyama, S. Hirao, S. Kuwabata, J. Electrochem. Soc. 139 (1992) 3141.

[17] F. Beck, M. Dalhaus, N. Zahedi, Electrochim. Acta 37 (1992) 1265.

[18] İ. Becerık, F. Kadirgan, J. Electroanal. Chem. 436 (1997) 189.

[19] P.A. Christensen, A. Hamnett, Electrochim. Acta 36 (1991) 8.

[20] E.W. Tsai, G.W. Jang, K. Rajeshwar, J. Chem. Soc., Chem. Commun. (1987) 1776.

[21] E.M. Genies, M. Marchesiello, G. Bidan, Electrochim. Acta 37 (1992) 1015.

[22] F.T.A. Vork, E. Barendrecht, Electrochim. Acta 35 (1990) 135.

[23] H. Laborde, J.M. Leger, C. Lamy, J. Appl. Electrochem. 24 (1994) 219.

[24] K.M. Kost, D.E. Bartak, B. Kazee, T. Kuwana, Anal. Chem. 60 (1988) 2379.

[25] A. Aramata, R. Ohnishi, J. Electroanal. Chem. 162 (1984) 153.

[26] D.J. Strike, N.F. de Rooij, M. Koudelka-Hep, M. Ulmann, J. Augustynski, J. Appl. Electrochem. 22 (1992) 922.

[27] H. Yang, T. Lu, K. Xue, S. Sun, G. Lu, S. Chen, J. Electrochem. Soc. 144 (1997) 2302.

[28] M. Gholamian, A.Q. Contractor, J. Electroanal. Chem. 281 (1990) 69.

[29] L.F. Warren, D.P. Anderson, J. Electrochem. Soc. 134 (1987) 101. 